\title{
Nothing in (sponge) biology makes sense - except when based on holotypes
}

\author{
DIRK ERPENBECK ${ }^{1,2}$, MERRICK EKINS ${ }^{3}$, NICOLE ENGHUBER ${ }^{1}$, JOHN N.A. HOOPER ${ }^{3,4}$, \\ HELMUT LEHNERT ${ }^{2,5}$, ANGELO POLISENO ${ }^{1}$, ASTRID SCHUSTER ${ }^{1}$, EDWIN SETIAWAN ${ }^{1,6}$, \\ NICOLE J. DE VOOGD ${ }^{7}$, GERT WÖRHEIDE ${ }^{1,8}$ AND ROB W.M. VAN SOEST $^{7}$ \\ ${ }^{1}$ Department of Earth and Environmental Sciences, Ludwig-Maximilians-Universität München, Richard-Wagner Str. 10, 80333 \\ Munich, Germany, ${ }^{2}$ GeoBio-Center ${ }^{\mathrm{LMU}}$, Richard-Wagner Str. 10, 80333, Munich, Germany, ${ }^{3}$ Natural Environments Program, \\ Queensland Museum, PO Box 3300, South Brisbane, Queensland 4101, Australia, ${ }^{4}$ Eskitis Institute for Drug Discovery, Griffith \\ University, Nathan, Queensland 4111, Australia, ${ }^{5}$ Eichenstr. 14, 86507 Oberottmarshausen, Germany, ${ }^{6}$ Zoology lab, Biology \\ Department, Mathematic and Natural Science Faculty, Sepuluh November Institute of Technology, Surabaya, Indonesia, ${ }^{7}$ Naturalis \\ Biodiversity Center, P.O. Box 9517, 2300 RA Leiden, the Netherlands, ${ }^{8}$ SNSB -Bavarian State Collections of Palaeontology and \\ Geology, Richard-Wagner Str. 10, 80333 Munich, Germany
}

\begin{abstract}
Sponge species are infamously difficult to identify for non-experts due to their high morphological plasticity and the paucity of informative morphological characters. The use of molecular techniques certainly helps with species identification, but unfortunately it requires prior reference sequences. Holotypes constitute the best reference material for species identification, however their usage in molecular systematics and taxonomy is scarce and frequently not even attempted, mostly due to their antiquity and preservation history. Here we provide case studies in which we demonstrate the importance of using holotype material to answer phylogenetic and taxonomic questions. We also demonstrate the possibility of sequencing DNA fragments out of century-old holotypes. Furthermore we propose the deposition of DNA sequences in conjunction with new species descriptions.
\end{abstract}

Keywords: Porifera, sponges, holotypes, molecular systematics, type material

Submitted 31 October 2014; accepted 30 March 2015; first published online 4 May 2015

\section{INTRDDUCTION}

Dobzhansky reminds us in his famous 1973 paper (for which our title is a homage) that evolution is the driving force for all biological phenomena (Dobzhansky, 1973). Evolution can be regarded as a continuous process of change. Similarly our understanding of evolution continuously changes as a result of rapid progress in research techniques. Typical examples from sponge evolutionary sciences can be deduced from the numerous changes in phylogenetic hypotheses. Sponge systematics was revolutionized with the introduction of cladistic analyses (e.g. Van Soest, 1987) and the use of molecular methods starting from single gene sequencing (Kelly-Borges et al., 1991) to phylogenomics (e.g. Philippe et al., 2009) (see for reviews and case studies e.g. Boury-Esnault, 2006; Erpenbeck et al., 2012a; Morrow et al., 2013). These molecular tools were soon regarded as the most promising source of phylogenetic characters to further our understanding in sponge evolutionary relationships. Morphological and chemotaxonomic characters displayed shortcomings due to environmental plasticity, homoplasy and lack of complexity, whereas ultrastructure was regarded as too laborious (see e.g. Maldonado et al., 1999; Boury-Esnault, 2006; Erpenbeck et al., 2006; Erpenbeck \& Van Soest, 2007; Cárdenas \&

Corresponding author:

D. Erpenbeck

Email: erpenbeck@lmu.de
Rapp, 2013). The subsequent phylogenetic trees of molecular data resulted in few (hexactinellid taxa), to dramatic changes (the other $92 \%$ of sponge species) in poriferan systematics (see e.g. Erpenbeck \& Wörheide, 2007; Wörheide et al., 2012; Redmond et al., 2013).

Phylogenetic trees provide the basis for exploring and understanding the current patterns and processes observed in all fields of sponge biology, and therefore constitute an important reference for the design of future research (including grant applications). However, publications on character evolution, biochemistry, phylogeny and all other aspects of biology have reduced credibility and impact when the underlying taxonomy is erroneous. In turn, the quality of every phylogenetic tree is dependent on the correct identification of its constituent taxa. While tree reconstruction algorithms advance and facilitate the modelling of molecular evolution scenarios, their underlying data frequently suffer from erroneous taxonomy. For example, DNA sequences submitted to NCBI GenBank (http://www.ncbi.nlm.nih.gov/genbank) are not subject to any taxonomic control and frequently bear incorrect taxon names (see e.g. Ashelford et al., 2005; Shen et al., 2013). This is in strong contrast to the function of public DNA repositories, such as the European Nucleotide Archive (http://www.ebi.ac. uk/ena), NCBI GenBank or the DNA Data Bank of Japan (http://www.ddbj.nig.ac.jp) as arguably the most important sources for sequences in molecular phylogenetic and taxonomic studies. Different specialized taxonomically curated databases aiming to minimize taxonomic ambiguities 
(e.g. the Sponge Barcoding Database, http://www.spongebarcoding.org; Wörheide et al., 2008) build up a reference backbone, which must rely on taxonomically correct reference material (Wörheide \& Erpenbeck, 2007).

The optimal taxonomic reference material for a species is the primary type, or holotype, i.e. the exact specimen used for the species description. The holotype is the single specimen upon which a new nominal species-group taxon is based (International Commission on Zoological Nomenclature (ICZN) 4th Edition, Article 73, 2012), that objectively defines the species concept, and fixes the name proposed by the original author in the original publication. The holotype (or any other secondary type specimen) is usually consulted in morphological taxonomy or systematics, but holotype examination in molecular studies is scarce. In the currently most comprehensive molecular phylogenetic trees for sponges, we find no mention of holotype examination.

Consequently, DNA sequences without unequivocal taxonomic identification are in the majority of cases published in phylogenetic trees and subsequently submitted to public DNA repositories. While the identification of the species from which the DNA was extracted and sequences produced may be subsequently revised and updated, these refinements are not necessarily made globally known, including in GenBank (and other repositories) itself. As such, these taxonomic errors are compounded in subsequent phylogenetic trees that use these sequence databases on the assumption that their original taxonomy was correct.

Conversely, using holotypes for molecular phylogenetic studies confers both taxonomic confidence and more rigour through compliance with the ICZN. Several reasons appear to influence the choice why holotypes are not the primary target for molecular systematic studies. Among the most obvious is the uncertain DNA quality due to age or history of preservation. DNA in the post-mortem cell is subject to a number of types of deterioration such as oxidative and hydrolytic damage, DNA crosslinks and microorganism nucleases (see for an overview Rizzi et al., 2012). These result in DNA fragmentation, amplification inhibition, or base deaminations leading to erroneous genotypes when PCR-amplified under standard protocols (see details in Hofreiter et al., 2001). Destructive processes increase during slow dehydration processes in which the nucleases stay active for some time, or when fixatives were used that trigger DNA-protein crosslinks (e.g. formalin; for extraction protocols see De Bruyn et al., 2011). These destructive processes can be reduced by rapid dehydration (such as preservation in ethanol, silica gel or quick air drying), to inhibit the nuclease activity. However, fragmentation to templates that cannot be amplified with standard primer sets, may prevent the inclusion of holotype sequences in phylogenetic datasets but does not hinder a molecular taxonomic comparison. Here, short DNA markers, 'minimalist DNA barcodes', specifically developed to amplify fragmented DNA templates for molecular taxonomy can facilitate the taxonomic verification of samples by comparison with the holotype prior to publication (Hajibabaei et al., 2006).

Another obstacle for recruiting holotypes in phylogenetic analysis was their accessibility. Discovering where the holotypes are located from historical and foreign language literature, including subsequent taxonomic revisions, potential synonymy, genus transfers etc., are complex and confusing processes. This obstacle is further exacerbated by the antiquity of the current sponge systematics, whereby most genera presently considered valid were fixed by their type species described in the late 19th century, in a scattered literature, and with rarely cited museum specimen numbers, requiring painstaking detective work decades or centuries later (see introductory discussion in (and online updates of) Hooper \& Wiedenmayer, 1994). Secondly, accessing the various museums, and then gaining permission to subsample holotypes increases the impediment to source them. However, for sponges there are presently highly comprehensive sources of taxonomic information ranging from the Systema Porifera (up to genus level; Hooper \& Van Soest, 2002), to dynamic online tools such as the World Porifera Database (up to subspecies level; Van Soest et al., 2011) that provide efficient tools to retrieve information on holotypes. Moreover, as DNA can be extracted from minimal amounts of tissue and from every sponge tissue with living cells, DNA sampling in sponges can be considered minimally destructive amongst most Metazoa.

A crude estimation of the number of sequences from holotypes used for sponge systematics undertaken prior to this study yielded less than 80 published sponge holotype sequences $\left(<_{1} \%\right.$ of all described valid sponge species; Van Soest et al., 2012). This is a remarkably low number for a phylum, whose species identification is difficult and challenged by high degrees of environmentally induced plasticity. Consequently, it is obvious that there is a lack of holotype sequences available to undertake precise identifications of taxa for all aspects of sponge research. In this paper we demonstrate the application and advantages of holotype sequences in sponge science based on various case studies, and make a strong argument for their increased use in the future.

\section{MATERIALS AND METHODS}

DNA of the following specimens have been extracted in the course of several different projects: MOM INV-22285 (04 0348) (holotype Heteroxya corticata Topsent, 1898), BMNH 1881.81.10.21.266 (neotype Xestospongia testudinaria), BMNH 1881.81.10.21.267 (associated specimen of Ridley's Xestospongia testudinaria), MCZ PORa-6449 and MCZ PORa-6450 (syntypes Xestospongia muta (Schmidt, 1870)), ZMB2889 (holotype Neopetrosia chaliniformis (Thiele, 1899)), BMNH 1898.12.20.49 (holotype Neopetrosia exigua (Kirkpatrick, 1900)), AM Z3867 (holotype Narrabeena lamellata (as Smenospongia lamellata Bergquist, 1980)), USNM 1231429 (holotype Stelletta anthastra Lehnert \& Stone, 2014). Specimens were either dry or preserved in ethanol with no further information on other fixatives applied such as formalin. DNA was either extracted using the Qiagen DNeasy Blood \& Tissue kit for the recently collected samples (Narrabeena lamellata, Stelletta anthastra) or Qiagen QiAmp Mini Kit (Heteroxya corticata) following the manufacturer's protocol, or a modified CTAB phenol-chloroform method (Porebski et al., 1997) with the phenol-octanol and RNase solutions steps skipped (Neopetrosia chaliniformis, Xestospongia testudinaria, Xestospongia muta). Preferable methods regarding DNA yield and amplification success could not be identified. Fragments of the mitochondrial cytochrome oxidase subunit 1 (CO1, standard barcoding fragment) were amplified using degenerated versions of universal barcoding primers: dgLCO1490 (GGT CAA CAA ATC ATA AAG AYA TYG G) 
and dgHCO2198 (TAA ACT TCAG GGT GAC CAA ARA AYC A) (Meyer et al., 2005) with an annealing temperature of $43^{\circ} \mathrm{C}$. Fragments of the mitochondrial cytochrome oxidase subunit 2 ( $\operatorname{cox} 2)$ were amplified using the primers $\mathrm{CO}_{2} \mathrm{~F}$ Por (TTT TTC ACG ATC AGA TTA TGT TTA) and CO2R Por (ATA CTC GCA CTG AGT TTG AAT AGG) (Rua et al., 2011) with an annealing temperature of $40^{\circ} \mathrm{C}$. Fragments of ATP6 were amplified using an internal primer set modified from Rua et al. (2011) (ATP6_Xt_f1: TAG GGG TAA CTT TGT TAG GG and ATP6_Xt_r1 CCA ATG AAA TAG CAC GAG CC) with an annealing temperature of $44^{\circ} \mathrm{C}$. Fragments of the nuclear ribosomal $28 \mathrm{~S}$ gene $\left(\mathrm{C}_{2}-\mathrm{D}_{2}\right)$ were amplified using the primers $28 \mathrm{~S}-\mathrm{C}_{2}$-fwd (GAA AAG AAC TTT GRA RAG AGA GT) and 28S-D2-rev (TCC GTG TTT CAA GAC GGG) (Chombard et al., 1998) with an annealing temperature of $50^{\circ} \mathrm{C}$. The $25 \mu \mathrm{L}$ PCR mix consisted of $5 \mu \mathrm{L} 5 \times$ green GoTaq ${ }^{\circledR}$ PCR Buffer (Promega Corp, Madison, WI), $4 \mu \mathrm{L}$ $25 \mathrm{mM} \mathrm{MgCl}_{2}$ (Promega Corp, Madison, WI), $2 \mu \mathrm{L} 10 \mathrm{mM}$ dNTPs, $2 \mu \mathrm{L}$ BSA $\left(100 \mu \mathrm{g} \mathrm{mL}^{-1}\right), 1 \mu \mathrm{l}$ each primer $(5 \mu \mathrm{M})$, $7.8 \mu \mathrm{L}$ water, $0.2 \mu \mathrm{L}$ GoTaq $^{\circledR}$ DNA polymerase $\left(5 \mathrm{u} \mu \mathrm{L}^{-1}\right)$ (Promega Corp, Madison, WI) and $2 \mu \mathrm{L}$ DNA template. The PCR regime comprised an initial denaturation phase of $94^{\circ} \mathrm{C}$ for 3 min followed by 35 cycles of $30 \mathrm{~s}$ denaturation at $94^{\circ} \mathrm{C}$, $20 \mathrm{~s}$ annealing and $60 \mathrm{~s}$ elongation at $72^{\circ} \mathrm{C}$ each and a final elongation at $72^{\circ} \mathrm{C}$ for $5 \mathrm{~min}$. Alternatively a two-step approach with 4 cycles of $45^{\circ} \mathrm{C}$ annealing temperature prior to 30 cycles of $50^{\circ} \mathrm{C}$ were applied. The PCR products were purified with the standard ammonium acetate-ethanol precipitation before cycle sequencing using the BigDye ${ }^{\circledR}$-Terminator v3.1 (Applied Biosystems) following the manufacturer's protocol. Both strands of the template were sequenced on an ABI 3730 automated sequencer. The poriferan origin of the sequences was checked by a BLAST search against the NCBI GenBank database (http://www.ncbi.nlm.nih.gov). Sequences were basecalled, trimmed and assembled in CodonCode Aligner $\mathrm{v}$ 3.7.1.1 and subsequently aligned with other representative sequences available from GenBank in MAFFT v7.149b (Katoh \& Standley, 2013). All sequences are deposited in the Sponge Barcoding Database (SBD, http://www.spongebarcoding.org; Wörheide et al., 2008) and in NCBI GenBank (see Results and Discussion). Maximum likelihood reconstructions were performed using RAxML 7.2.5 (Stamatakis, 2006) under the GTR model of nucleotide substitution with CAT approximation of rate heterogeneity and 100 fast bootstrap replicates.

\section{RESULTS AND DISCUSSIDN}

\section{Age doesn't (always) matter: BLAST the past}

DNA was amplified for all of the above-mentioned type material, including specimens collected in the 19th century. For example $\mathrm{CO}_{1}$ and $28 \mathrm{~S}$ rDNA sequences were successfully retrieved from Heteroxya corticata collected in 1895, which is the type taxon for the family Heteroxyidae Dendy 1905 (SBD\# 1152; NCBI accession number KP939318). Likewise, successful amplification of the holotypes of Neopetrosia chaliniformis (collected by Sarasin in Sulawesi between 1893-1896 and described as Petrosia chaliniformis by Thiele in 1899; SBD\# 1153; NCBI: KMo30103), and Neopetrosia exigua (collected 1898; SBD\# 1154, NCBI: KMo30104), and type material of the Caribbean barrel sponge Xestospongia muta Schmidt (described 1870; SBD\# 1155, \#1156; NCBI: KMo14756), and neotype and associated material of its Indo-Pacific congener Xestospongia testudinaria, collected in 1881 (see Ridley, 1884) (e.g. SBD\#1157, \#1158; NCBI: KMo14764; see also publications of Setiawan et al. in this volume).

Consequently, there is no reason to assume a priori that the antiquity of holotypes, their uncertain preservation history, and the likelihood of strong DNA degradation and fragmentation is a hindrance for successful DNA amplification and sequencing. In fact, DNA quality in old samples might be sufficient for amplification of standard phylogenetic markers if the tissue was stored in ethanol immediately or quickly dried. To our knowledge the first century-old sponge holotype successfully amplified was the holotype of Topsentia halichondrioides (as Trachyopsis halichondrioides Dendy, 1905), collected 1902, and used for phylogenetic analyses of halichondrid demosponges. Standard phylogenetic markers of $28 \mathrm{SrDNA}$, cytochrome oxidase subunit 1 , and the elongation-factor 1-alpha were successfully amplified (e.g. Erpenbeck et al., 2006) (SBD\# 1159; NCBI: e.g. AY625676).

Type material, if successfully amplified, is also prone to further contamination, particularly if it is more frequently subject to examination by taxonomists and therefore more likely exposed to contamination, including the metabolomics profile of the taxonomist(s) in question. In particular the use of universal primers such as degenerated $\mathrm{CO}_{1}$ barcoding primers (e.g. Meyer et al., 2005) result in increased yield of non-sponge sequences, which in turn should be easily detectable by phenetic controls like BLAST (Altschul et al., 1990), and these should be followed by (probabilistic) cladistic treebased methods to ascertain the poriferan origin of the DNA template (see Erpenbeck et al., 2002).

\section{Setting (chemo)taxonomy straight: Narrabeena IS a black sheep among Verongida}

Species of the order Verongida are frequently subject to biochemical research as they produce bromotyrosines (among other biochemical compounds), which possess bioactive properties of major interest for pharmaceutical research (see for a recent example Mani et al., 2012). Bromotyrosines have been discovered in all genera of Verongida since the morphological revision sensu Bergquist \& Cook (2002), which suggested an apomorphic nature of this character (Bergquist \& Cook, 2002) (see also Van Soest \& Braekman, 1999; Erpenbeck \& Van Soest, 2007). Narrabeena Cook \& Bergquist, 2002 is currently classified in the dictyoceratid family Thorectidae, and was erected for Smenospongia lamellata, which possesses fibres with a high amount of pith, unlike $S$. aurea, the type species of Smenospongia. Smenospongia has been regarded as the 'point of closest similarity between Verongida and Dictyoceratida' (Bergquist, 1980). Nevertheless, despite its verongid morphology, Narrabeena was placed into Dictyoceratida due to the absence of bromotyrosines. Recent CO1 and $28 \mathrm{~S}$ rDNA reconstructions, however, resolved Narrabeena, investigated in a molecular dataset for the first time, with Verongida (Erpenbeck et al., 2012b). Independent $18 \mathrm{~S}$ analyses, however, using a different specimen set recovered a Narrabeena sample among Dictyoceratida, and implied the need for reanalysis using a conclusive dataset (Redmond et al., 2013). Consequently we analysed the holotype specimen (AM $\mathrm{Z}_{3}$ 867) from the Australian Museum, Sydney, with molecular methods and yielded a fragment of the $\mathrm{C}_{1}-\mathrm{D}_{2}$ region of $28 \mathrm{~S}$ 




Fig. 1. Maximum likelihood phylogram of the $28 \mathrm{~S}$ fragment of Narabeena lamellata (bold) and representative dictyoceratid and verongid demosponge sequences as retrieved from GenBank. Numbers above the branches are bootstrap support values $>70$.

rDNA and for CO1 (SBD \#1160; NCBI: KP939316). The phylogenetic analyses recovered $\mathrm{AM} \mathrm{Z}_{3} 867$ within the Verongida in close relationship to Suberea, Aplysina and Porphyria and distant to the dictyoceratid samples of the dataset with both markers (see $28 \mathrm{~S}$ rDNA tree in Figure 1 ). The inclusion of the $N$. lamellata holotype sequence in this analysis therefore clearly shows the verongid relationships of Narrabeena and justifies its transfer to Verongida. The analysis also confirms that absence/presence patterns of secondary metabolites in chemotaxonomy have to be evaluated carefully. Besides the independent production of bromotyrosines in other lineages (see review in Erpenbeck \& Van Soest, 2007), secondary metabolite production can easily be switched off by mutations in the biosynthetic pathway and its regulatory elements.

\section{Young holotypes of an old phylum: new species with molecular registrations}

Molecular methods keep advancing throughout all aspects of sponge biology and molecular taxonomy will likely become the standard for species identification and description in the future. The description of new sponge (and most other metazoan) species will remain predominantly descriptive in the foreseeable future but barcoding approaches and molecularly 
supported museum database platforms (e.g. Atlas of Living Australia, see Hooper et al., 2013) also provide various molecular information for the samples. As the costs for DNA barcoding are comparatively low (see e.g. Vargas et al., 2012), sequences can be easily associated with the species descriptions for subsequent analyses, even when the molecular data itself might not be incorporated into species description (which we do not advocate). Examples are the recent publications of Alaskan (Aleutian) sponges (Lehnert \& Stone, 2013; Lehnert \& Stone, 2014), for which sequences of the mitochondrial $\mathrm{CO}_{1}$ (Barcoding fragment) and $28 \mathrm{~S}$ rDNA (C1-D2 and $\mathrm{D}_{3}-\mathrm{D}_{5}$ fragment; SBD\# 1161; NCBI: e.g. KP939317) are submitted to the Sponge Barcoding Database. With this information included, phylogenetic trees can be reconstructed by anyone interested, or deducted directly from the Sponge Genetree Server (http://www.spongegenetrees.org; Erpenbeck et al., 2008).

For such a procedure it is evident that samples (or a designated fragment of the sample) are immediately and optimally preserved after collection for molecular purposes in order to keep the DNA amplifiable. Immediate placement in ethanol (as highly concentrated as possible) with ethanol exchange after $24 \mathrm{~h}$ (as the seawater dilutes the ethanol) followed by cool storage is among the most practicable and economic methods, with immediate freezing or alternatively the preservation of small sponge crumbles in silica powder (Alvarez et al., 2000), or as well storage in high-salt/DMSO buffer (Seutin et al., 1991; Dawson et al., 1998) also economic and effective.

\section{CONCLUSION}

The use of primary type material, and preferably also secondary types for unequivocal verification of the sponge species identification, should be considered for all aspects of evolutionary research, to build a more reliable baseline dataset upon which all new sponge molecular identifications are compared. Although older type material is traditionally infamous amongst many practitioners of molecular barcoding, for the alleged difficulties in achieving conclusive molecular data, we show here that even standard methods may frequently succeed with antiquated specimens. Optimally, molecular identification should be attempted in parallel with comparison with DNA from holotypes. The corollary is that sequence data of non-type specimens without corroboration from type material must be more cautiously interpreted in terms of the power of the evidence they present and the impact on higher systematic interpretation.

\section{ACKNOWLEDGEMENTS}

We thank Christine Morrow (Queen's University, Belfast), Michèle Bruni (Oceanographic Museum of Monaco), Simone Schätzle and Gabriele Büttner (LMU) for various contributions to this study. Jane Fromont (WA Museum) and an anonymous reviewer improved the quality of this manuscript.

\section{FINANCIAL SUPPDRT}

We would like to acknowledge funding of the Lehre@LMU programme of the Ludwig-Maximilians University Munich.

\section{REFERENCES}

Altschul S.F., Gish W., Miller W., Myers E.W. and Lipman D.J. (1990) Basic local alignment search tool. Journal of Molecular Biology 215 , 403-410.

Alvarez B., Crisp M.D., Driver F., Hooper J.N.A. and Van Soest R.W.M. (2000) Phylogenetic relationships of the family Axinellidae (Porifera: Demospongiae) using morphological and molecular data. Zoologica Scripta 29, 169-198.

Ashelford K.E., Chuzhanova N.A., Fry J.C., Jones A.J. and Weightman A.J. (2005) At least 1 in 2016 S rRNA sequence records currently held in public repositories is estimated to contain substantial anomalies. Applied and Environmental Microbiology 71, 7724-7736.

Bergquist P.R. (1980) A revision of the supraspecific classification of the orders Dictyoceratida, Dendroceratida, and Verongida (class Demospongiae). New Zealand Journal of Zoology 7, 443-503.

Bergquist P.R. and Cook S.d.C. (2002) Order Verongida Bergquist, 1978. In Hooper J.N.A. and Van Soest R.W.M. (eds) Systema Porifera. A guide to the classification of sponges, Volume 1. New York: Kluwer Academic/Plenum Publishers, pp. 1081.

Boury-Esnault N. (2006) Systematics and evolution of Demospongiae. Canadian Journal of Zoology-Revue Canadienne de Zoologie 84, 205-224.

Cárdenas P. and Rapp H.T. (2013) Disrupted spiculogenesis in deepwater Geodiidae (Porifera, Demospongiae) growing in shallow waters. Invertebrate Biology 132, 173-194.

Chombard C., Boury-Esnault N. and Tillier S. (1998) Reassessment of homology of morphological characters in tetractinellid sponges based on molecular data. Systematic Biology 47, 351-366.

Dawson M.N., Raskoff K.A. and Jacobs D.K. (1998) Field preservation of marine invertebrate tissue for DNA analyses. Molecular Marine Biology and Biotechnology 7, 145-152.

De Bruyn M., Parenti L. and Carvalho G. (2011) Successful extraction of DNA from archived alcohol-fixed white-eye fish specimens using an ancient DNA protocol. Journal of Fish Biology 78, 2074-2079.

Dendy A. (1905) Report on the sponges collected by Professor Herdman, at Ceylon, in 1902. In Herdman W.A. (ed) Report to the Government of Ceylon on the pearl oyster fisheries of the Gulf of Manaar, Volume 3. London: Royal Society, pp. 57-246.

Dobzhansky T. (1973) Nothing in biology makes sense except in the light of evolution. The American Biology Teacher 35, 125-129.

Erpenbeck D., Breeuwer J.A.J., Parra-Velandia F.J. and Van Soest R.W.M. (2006) Speculation with spiculation? - Three independent gene fragments and biochemical characters versus morphology in demosponge higher classification. Molecular Phylogenetics and Evolution 38, 293-305.

Erpenbeck D., Breeuwer J.A.J., van der Velde H.C. and Van Soest R.W.M. (2002) Unravelling host and symbiont phylogenies of halichondrid sponges (Demospongiae, Porifera) using a mitochondrial marker. Marine Biology 141, 377-386.

Erpenbeck D., Hall K., Alvarez B., Büttner G., Sacher K., Schätzle S., Schuster A., Vargas S., Hooper J.N.A. and Wörheide G. (2012a) The phylogeny of halichondrid demosponges: past and present re-visited with DNA-barcoding data. Organisms Diversity \& Evolution 12, 57-70.

Erpenbeck D., Sutcliffe P., Cook S.d.C., Dietzel A., Maldonado M., van Soest R.W.M., Hooper J.N.A. and Wörheide G. (2012b) Horny sponges and their affairs: on the phylogenetic relationships of keratose sponges. Molecular Phylogenetics and Evolution 63, 809-816.

Erpenbeck D. and Van Soest R.W.M. (2007) Status and perspective of sponge chemosystematics. Marine Biotechnology 9, 2-19. 
Erpenbeck D., Voigt O., Gültas M. and Wörheide G. (2008) The sponge genetree server - providing a phylogenetic backbone for poriferan evolutionary studies. Zootaxa 1939, 58-60.

Erpenbeck D. and Wörheide G. (2007) On the molecular phylogeny of sponges (Porifera). Zootaxa, 1668, 107-126.

Hajibabaei M., Smith M., Janzen D.H., Rodriguez J.J., Whitfield J.B. and Hebert P.D. (2006) A minimalist barcode can identify a specimen whose DNA is degraded. Molecular Ecology Notes 6, 959-964.

Hofreiter M., Jaenicke V., Serre D., von Haeseler A. and Päbo S. (2001) DNA sequences from multiple amplifications reveal artifacts induced by cytosine deamination in ancient DNA. Nucleic Acids Research 29, 4793-4799.

Hooper J.N.A., Hall K.A., Ekins M., Erpenbeck D., Wörheide G. and Jolley-Rogers G. (2013) Managing and sharing the escalating number of sponge "unknowns": the SpongeMaps Project. Integrative and Comparative Biology 53, 473-481.

Hooper J.N.A. and Van Soest R.W.M. (2002) Systema Porifera: a guide to the classification of sponges. New York: Kluwer Academic/Plenum Publishers.

Hooper J.N.A. and Wiedenmayer F. (1994) Porifera. In Wells A. (ed) Zoological catalogue of Australia, Volume 12. [Revised online version $2004 \mathrm{http} / /$ www.environment.gov.au/biodiversity/abrs/online-resources/ fauna/afd/taxa/porifera/] Melbourne: CSIRO, pp. 1-621.

ICZN (2012) Amendment of Articles 8, 9, 10, 21 and 78 of the International Code of Zoological Nomenclature to expand and refine methods of publication. ZooKeys 219, 1-10.

Katoh K. and Standley D.M. (2013) MAFFT Multiple sequence alignment software version 7 : improvements in performance and usability. Molecular Biology and Evolution 30, 772-780.

Kelly-Borges M., Bergquist P.R. and Bergquist P.L. (1991) Phylogenetic relationships within the order Hadromerida (Porifera, Demospongiae, Tetractinomorpha) as indicated by ribosomal-RNA sequence comparisons. Biochemical Systematics and Ecology 19, 117-125.

Kirkpatrick R. (1900) On the Sponges of Christmas Island. Proceedings of the Zoological Society of London 1900, 127-141, pls XII-XIII.

Lehnert H. and Stone R.P. (2013) Four new species of Haplosclerida (Porifera, Demospongiae) from the Aleutian Islands, Alaska. Zootaxa 3700, 573-582.

Lehnert H. and Stone R.P. (2014) Aleutian Ancorinidae (Porifera, Astrophorida): description of three new species from the genera Stelletta and Ancorina. Zootaxa 3826, 341-355.

Maldonado M., Carmona M.C., Uriz M.J. and Cruzado A. (1999) Decline in Mesozoic reef-building sponges explained by silicon limitation. Nature 401, 785-788.

Mani L., Jullian V., Mourkazel B., Valentin A., Dubois J., Cresteil T., Folcher E., Hooper J.N.A., Erpenbeck D., Aalbersberg W. and Debitus C. (2012) New antiplasmodial bromotyrosine derivatives from Suberea ianthelliformis Lendenfeld, 1888. Chemistry and Biodiversity 9, 1436-1451.

Meyer C.P., Geller J.B. and Paulay G. (2005) Fine scale endemism on coral reefs: archipelagic differentiation in turbinid gastropods. Evolution 59, 113-125.

Morrow C.C., Redmond N.E., Picton B.E., Thacker R.W., Collins A.G., Maggs C.A., Sigwar J.D. and Allcock A.L. (2013) Molecular phylogenies support homoplasy of multiple morphological characters used in the taxonomy of Heteroscleromorpha (Porifera: Demospongiae). Integrative and Comparative Biology 53, 428-446.

Philippe H., Derelle R., Lopez P., Pick K., Borchiellini C., Boury-Esnault N., Vacelet J., Deniel E., Houliston E., Quéinnec E., DaSilva C., Wincker P., Le Guyader H., Leys S., Jackson D.J.,
Schreiber F., Erpenbeck D., Morgenstern B., Wörheide G. and Manuel M. (2009) Phylogenomics restores traditional views on deep animal relationships. Current Biology 19, 706-712.

Porebski S., Bailey L.G. and Baum B. (1997) Modification of a CTAB DNA extraction protocol for plants containing high polysaccharide and polyphenol components. Plant Molecular Biology Reporter 15 , $8-15$.

Redmond N.E., Morrow C.C., Thacker R.W., Díaz M.C., Boury-Esnault N., Cárdenas P., Hajdu E., Lobo-Hajdu G., Picton B.E., Pomponi S.A., Kayal E. and Collins A.G. (2013) Phylogeny and systematics of Demospongiae in light of new small-subunit ribosomal DNA (18S) sequences. Integrative and Comparative Biology 53, 388-415.

Ridley S.O. (1884) Spongiida. London: British Museum (Natural History).

Rizzi E., Lari M., Gigli E., De Bellis G. and Caramelli D. (2012) Ancient DNA studies: new perspectives on old samples. Genetics, Selection, Evolution 44, 21

Rua C.P.J., Zilberberg C. and Sole-Cava A.M. (2011) New polymorphic mitochondrial markers for sponge phylogeography. Journal of the Marine Biological Association of the United Kingdom 91, 1015-1022.

Schmidt E.O. (1870) Grundzüge einer Spongien-Fauna des Atlantischen Gebietes. Leipzig: Wilhelm Engelmann.

Seutin G., White B.N. and Boag P.T. (1991) Preservation of avian blood and tissue samples for DNA analyses. Canadian Journal of Zoology 69, $82-90$.

Shen Y., Chen X. and Murphy R. (2013) Assessing DNA barcoding as a tool for species identification and data quality control. PLOS ONE 8, e57125.

Stamatakis A. (2006) RAxML-VI-HPC: maximum likelihood-based phylogenetic analyses with thousands of taxa and mixed models. Bioinformatics 22, 2688-2690.

Thiele J. (1899) Studien über pazifische Spongien. II. Ueber einige Spongien von Celebes. Zoologica. Original-Abhandlungen aus dem Gesamtgebiete der Zoologie 24, 1-33. pls I-V.

Topsent E. (1898) Éponges nouvelles des Açores (Première Série). Mémoires de la Société Zoologique de France 11, 225-255.

Van Soest R.W.M. (1987) Phylogenetic exercises with monophyletic groups of sponges. In Vacelet J. and Boury-Esnault N. (eds) NATO ASI series, Volume G13. Berlin: Springer, pp. 227-241.

Van Soest R.W.M., Boury-Esnault N., Hooper J.N.A., Rützler K., de Voogd N.J., Alvarez de Glasby B., Hajdu E., Pisera A., Manconi R., Schönberg C., Janussen D., Tabachnick K.R., Klautau M., Picton B. and Kelly M. (2011) World Porifera database. Available online under http://www.marinespecies.org/porifera.

Van Soest R.W.M., Boury-Esnault N., Vacelet J., Dohrmann M., Erpenbeck D., De Voogd N.J., Santodomingo N., Vanhoorne B., Kelly M. and Hooper J.N.A. (2012) Global diversity of sponges (Porifera). PLoS ONE 7, e35105.

Van Soest R.W.M. and Braekman J.C. (1999) Chemosystematics of Porifera: a review. Memoirs of the Queensland Museum 44, 569-589.

Vargas S., Schuster A., Sacher K., Büttner G., Schätzle S., Läuchli B., Hall K., Hooper J.N.A., Erpenbeck D. and Wörheide G. (2012) Barcoding sponges: an overview based on comprehensive sampling. PLOS ONE 7, e39345.

Wörheide G., Dohrmann M., Erpenbeck D., Larroux C., Maldonado M., Voigt O., Borchiellini C. and Lavrov D. (2012) Deep phylogeny and evolution of sponges (Phylum Porifera). Advances in Marine Biology 61, 1-78.

Wörheide G. and Erpenbeck D. (2007) DNA taxonomy of sponges progress and perspectives. Journal of the Marine Biological Association of the United Kingdom 87, 1629-1633. 
and

Wörheide G., Erpenbeck D. and Menke C. (2008) The Sponge Barcoding Project - aiding in the identification and description of poriferan taxa. In Custódio M.R., Lôbo-Hajdu G., Hajdu E. and Muricy G. (eds) Porifera research: biodiversity, innovation \& sustainability. Rio de Janeiro: Museu Nacional de Rio de Janiero Book Series, pp. 123-128.

\section{Correspondence should be addressed to:}

D. Erpenbeck

Department of Earth and Environmental Sciences, LudwigMaximilians-Universität München, Richard-Wagner Str. 10, 80333 Munich, Germany email: erpenbeck@lmu.de 